\title{
The Role of Improving Water Use Efficiency in Irrigated Agriculture for Enhancing the Production and Productivity of the Crops
}

\author{
Amare Assefa Bogale* Abrham Wondifraw Sahle \\ College of Agriculture and Environmental Sciences, Department of Horticulture, Debark University \\ PO. Box 90, Debark, Ethiopia
}

\begin{abstract}
Water scarcity and the increasing global demand for water in many sectors, including agriculture, has become a global concern .The rapid growth world population and the adverse impacts of climate change lade to growing computation for water use by industrial and urban users for agriculture to secure enough food. Irrigated agriculture is an important role in total agriculture and provides humanity with wide range of agricultural products, including fruits, vegetables, grains and cereals. Effective management of water use is the only way to save water for the increasing irrigated agriculture. Different approaches have been adopted to reduce the damage caused by drought; among these approaches is water productivity or water use efficiency WUE. A crop with high WUE should have greater yield than crop with low WUE.
\end{abstract}

Keywords: water use efficiency, drought, irrigated agriculture, plant improvement

DOI: $10.7176 / \mathrm{JNSR} / 9-23-03$

Publication date: December $31^{\text {st }} 2019$

\section{Introduction}

Water productivity is the ratio of the net benefits from crop, forestry, fishery, livestock and mixed agricultural systems to the amount of water used to produce those benefits. In its broadest sense, it reflects the objectives of producing more food, income, livelihood and ecological benefits at less social and environmental cost per unit of

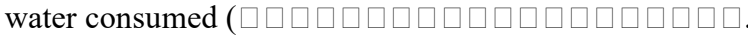

Improving water use efficiency or enhancing agricultural water productivity is a critical response to growing water scarcity, including the need to leave enough water in rivers and lakes to sustain ecosystems and to meet the growing demands of cities, industries and crop yields. Originally, crop physiologists defined water use efficiency as the amount of carbon assimilated and crop yield per unit of transpiration and then later as the amount of biomass or marketable yield per unit of evapotranspiration (Viets, 2008).

Irrigation scientists and engineers have used the term water (irrigation) use efficiency to describe how effectively water is delivered to crops and to indicate the amount of water wasted at plot, farm, command or system level and defined it as "the ratio of irrigation water transpired by the crops of an irrigation farm or project during their growth period to the water diverted from a river or other natural source into the farm or project canal or canals during the same period of time. This approach was further improved by introducing the concepts of uniformity, adequacy, and sagacity of irrigation. Some scholars have even pointed out that the commonly described relationship between water (input, $\mathrm{mm}$ or $\mathrm{ML}$ ) and agricultural product (output, $\mathrm{kg}$ or ton) is an index, and not efficiency. Still this concept of water use efficiency provides only a partial view because it does not indicate the total benefits produced, nor does it specify that water lost by irrigation is often reused by other users (Seckler $e t$ al., 2010).

More than $40 \%$ of global land is under arid or semi arid climatic conditions (Gamo, 2009). In the arid and semi-arid environments water is the most limiting factor in reducing agricultural production (Cattivelli et al.,2008). Drought is a complex process that needs to be understood by many disciplines in order to overcome and minimize the damage that it causes. The response of plant to drought is also complex. Because conditions vary in the frequency of dray and periods, the degree and timing of drought and the patterns of soil and atmospheric water deficits (Boutraa, 2010 a,b).

Drought is a kind of water stress that is related to other stresses, such as high temperature stress, salt stress, cold stress and so on (Sho et al., 2005) and that what made drought more complicated. Currently, drought research has been one of the main priorities in plant breeding programs worldwide. Over the past forty years many crop breeders and plant physiologists have made great efforts to improve the drought tolerance of arrange of agricultural and horticultural crops. Shortage of water at different scales lead to drought with all its agricultural impacts (Morison et al; 2008) and the climate has made the situation worse by reducing the amount of rain fall and therefore the amount of water available to agriculture (Ipcc, 2007). Shortage of water has forced the decision makers and particularly in countries with less water, to reduce the water use in agriculture, As a result farmer are face with legislative restrictions on use of water (Morison et al; 2008).

For better use of water in agriculture in water limited environments ,efforts are needed for different research 
disciplines; plant breeders, plant physiologists, agronomists ,plant bio technologists, water engineers and experts, to develop new approaches in water use. For example, it is possible to find or develop crops that require less water and maintaining high yield productivity. Many scientists are skeptical of the role of genetic engineering and bio technology in improving water use efficiency; because the manipulation of few single gen is unlikely to significant contribute in the improvement of such complex trait (Perry et al., 2005). one of the main breeding adapted approach to breeding for drought tolerance to over com the impact of water shortage on agricultural production is to concentrate on increasing what has come to be known as water productivity or water use efficiency (WUE) of the crop which is defined as productivity term output of crop per unit of water (Jones, 2004). Therefore the purpose of this paper is to review the role of improvement of water use efficiency in irrigated agriculture for the production and productivity of the crops.

\section{Role of Irrigated Agriculture}

Like rain fed agriculture, irrigated agriculture also plays a major role in food production, and also provides livelihoods for millions of poor farmers in developing countries. Irrigated agriculture currently provides $40 \%$ of the global cereal supply ( $60 \%$ of the cereals produced in developing countries). Worldwide, about $38 \%$ of the gross value of production comes from irrigated areas, which make up 29\% of the harvested area. Many observers expect that the contribution of irrigated agriculture to food production and rural development will increase in the coming decades (Bruinsma, 2003; Seckler et al., 2000). Perceptions of the costs and benefits of irrigation have changed markedly during the past 50 years (Faure et al., 2007), contributing to a decline in public investments in irrigation during the $1990 \mathrm{~s}$. After a decade of decline, the last few years have seen an increasing interest in public funding in water infrastructure for agriculture, particularly in Asia and in sub-Saharan Africa, where irrigation development is limited and the potential for improving access to irrigation water remains large. Reasons for the renewed interest include concerns regarding climate change induced rainfall variability; maintaining the existing infrastructure; potential for poverty alleviation; the high potential to improve performance and the recent concerns regarding food prices and availability(Faures et al., 2007).

Agriculture is the larger consumer of water, as around $70 \%$ of all fresh water withdrawals are used for food production (Calzadilla et al., 2010). The irrigated areas represents approximately $18 \%$ of the total crop land in 2003 (FAOSTAT, 2006), resulting in the production of 40-50\%of the food worldwide (Doll and Siebert, 2002). Irrigation has long been considered to be wistful, because of an necessary high amount of water use. The objective of the irrigation is to meet the evapo transpiration requirements of a crop ,by apply sufficient amount of water in the soil taking in consideration the local climate, the density of plant cover and [the growth stage of the crop (Perry et al.,2009).

In arid and semi arid environment, regions 'with less rain fall, there is an increase computation for water between agriculture and other water users (De Fraiture and Wichelns, 2010). Agriculture water use has 'grown in recent decades due to the increase in global population and the change in the type of food that require moire water than traditional foods (Molden, 2007).A range of strategies need to be implemented globally to reduce the impacts of water scarcity in agriculture. These could be implemented to collaboration between through research organizations and decision makers (Molden, 2007).

\subsection{Biophysical background of water productivity (WP) at the plant scale}

Assessing the scope for gains in water productivity requires an understanding of basic biological and hydrological crop-water relations. How much more water will be needed for agriculture in the future is governed, to a large extent, by links between water, food and changes in diets. The amount of water that we consume when eating food depends on diet and also on the water productivity of the agriculture production system. The amount of water required for field crops and its relation to yield dominates the equation on the need for additional water for food.

For a given crop variety and climate there is a well-established linear relationship between plant biomass and transpiration (Steduto et al., 2007). Different kinds of plants are more water efficient in terms of the ratio between biomass and transpiration. More biomass production requires more transpiration because when stomata open, carbon dioxide flows into the leaves for photosynthesis and water flows out. Water outflow is essential for cooling and for creating liquid movement in the plant for transporting nutrients. Stomata close during drought, thereby limiting transpiration, photosynthesis and production. The most common crops, C3 crops such as wheat and barley, are less water-efficient than $\mathrm{C} 4$ crops such as maize and sugarcane. The most water-efficient crops are the CAM (crassulacean acid metabolism) crops such as cactus and pineapple. These different plant types (C3, C4 and CAM) have evolved according to their different environments, and are classified primarily based on how they fix carbon dioxide in the photosynthetic process (Steduto et al., 2007).

To boost economic yield, plant breeders have developed varieties with a higher harvest index (the ratio of marketable grain yield to total crop biomass), achieving more economic produce per unit of transpiration. This breeding strategy has probably raised the potential for gains in water productivity more than any other agronomic practice over the last 40 years (Keller and Seckler, 2004). The harvest index for wheat and maize rose from about 
0.35 before the 1960s to 0.5 in the 1980s (Sayre et al., 1997), when plant breeders of the green revolution focused their attention on these crops. But the rate of increase in the harvest index has slowed over the last 20 years as physiological limits are being reached, and, thus, there has been a slowdown in the rate of gains in water productivity that are achieved through this method. In situations where yield is less than $40-50 \%$ of the potential, non-water factors such as soil fertility limit yield and crop water productivity per unit of ET (Tanner and Sinclair, 1983).

Land degradation and nutrient depletion significantly constrain opportunities to increase water productivity. In these situations there is a synergistic effect when water practices that increase access to water at the right time or reduce land degradation processes are combined with other agronomic practices such as maintaining soil health and fertility, controlling weeds and disease and the timing of planting. Such synergistic interactions between production factors raise water productivity, especially when yield values are low, because most production resources are used more efficiently as yield levels rise (de Wit, 1992).

\subsection{Impacts of Climate Change on Irrigation Requirements}

The requirement for irrigation water would be affected by the variation of meteorological effects under the conditions of climate change, and irrigation water will always be the major portion of the water consumption. Based on the projections and a water balance model in paddy fields, the future crop water requirement, effective rainfall and the demand for water for irrigation can be calculated. A comparison between the present (2004-2011) and the future (2046-2065) clearly shows that climate change would lead both rainfall and the temperature to rise; this would cause effective rainfall and crop water requirement to increase during cropping seasons in the future (Jyun-Long Lee and Wen-Cheng Huang, 2014).

To estimate how long term irrigation requirements average might change due to the expected climate change conditions of the 2020s, a global model of irrigation requirement, GIM(Global Irrigation Model) has been implemented (Doll and Siebert,2002). The climate impute of the GIM is based on long term observation of monthly values of precipitation, temperature, sunshine hours and number of wit days (Doll, 2002).

\subsection{Water Use Efficiency}

Water use efficiency (WUE) or water productivity has emerged from the idea of drought resistance and drought tolerance (Passioura, 2006). At the beginning of the sixties of the last century, water use efficiency has been generally define in agronomy (Viets, 2008) as:

WUE $=$ Crop yield (usually the economic yield)

Water used to produce the yield

The term water use efficiency can be used at wide range of scales; for example, it can be used at the farm, the field, the plant or down to the plant part levels, such as the leaf (Morison et al., 2008). In agriculture, WUE can be used at different levels; at leaf level (leaf photosynthesis rate per transpiration rate), at whole plat level (the ratio of total dray mass to water use) and at the final economic yield (crop grain per unit area to transpiration) (Hong-Xing et al., 2007; Ali and Talukder, 2008). In crop production the aim of improving WUE, is to produce more economic yield with less water when water is a limiting factor (Boutraa and Sanders, 2001a; Boutra, 2010a), such as in arid and semi arid regions across the globe.

\subsection{Saving Water for Irrigation Agriculture}

Water saving agriculture, is a notion to describe the combination of agronomic, physiological, bio technological/genetic and engineering approaches to reduce agricultural water use (Morison et al., 2008). Many workers focused on reducing the use of irrigation in hot, dray environments, as in these environments agriculture products require high water use due to the high rate of evapo-transpiration (Wallace; Gregory, 2004).Improving water use efficiency implies how effectively we can increase the out com of the crop with the current available water (Passioura, 2006; Ali and Talukder, 2008).

At the global level, the major grain exporters (USA, Canada, France, Australia and Argentina) produce grains in highly productive rain fed lands and the major grain importers rely on irrigation to produce grains (De Fraiture and Wichelns, 2010). The main strategy that needs to implemented in improving water productivity in rain fed agriculture is the wise management of crops and water resources in addition to the improvement of genetic makeup of crops to maximize the capture of water in plant bio mass production (Passioura, 2006). Whereas in irrigated land there is a need to better manage and use water efficiently, not only because of water shortage but also to maintain or reserve the environment (Karoun and EL-Mourid, 2009). Farmers are required to be motivated in order to increase water productivity through technical assistance, capacity building and the right to incentives and policies (De Fraiture and Wichelns, 2010). Improving crop water productivity relies not only water management, but it involves arrange of practice. Ali and Talukder (2008) summarized the techniques and practices that can be used to improve water productivity .These includes: deficit irrigation, proper sequencing of water deficit, surge irrigation in verity soil, increasing soil fertility, improving harvest index, manipulation seedling age, priming or 
shocking of seed, application of organic matter, tillage and sub soiling, water harvesting irrigation, crop selection, modernization of irrigation system and integrating agriculture-aquaculture.

\subsection{A key Opportunities for Improving Water Productivity or water Use Efficiency}

Key opportunities for improving water productivity in irrigated agriculture include, structural measures such as improving irrigation efficiency using micro-irrigation systems. In addition, it is essential to prevent seepage losses in the conveyance system and reduce evaporation during conveyance in areas where water is scarce. Actual losses depend on the state of the delivery network, and its engineering and management practices. After water arrives at the farm, it is sometimes temporarily stored, for example in night reservoirs, but more often it is directly distributed to the fields for irrigation. Losses at this stage are also due to leakage and evaporation. Losses in the application of water to famers' fields depend on the type of irrigation system, e.g. furrow, sprinkler or drip irrigation. Good water management requires that irrigation application do not exceed the amount of water that can be stored in the root zone (Jacob et al., 2009).

In irrigated crop production, farmers can reuse drainage water and (treated) wastewater, while minimizing pre-planting irrigation, and managing the amount of water that infiltrates the soil and is stored in the root zone. Another approach to improving irrigated agriculture is to support high input irrigated production using high yielding varieties, fertilizers, pesticides and other inputs. This is increasingly difficult to achieve, as irrigation development in sub-Saharan Africa is expensive. Irrigated systems have been widely criticized for low efficiency in their use of water and the corollary is therefore that opportunities exist to increase water productivity. However, it is important to avoid problem shifting and recognize that apparent water losses may appear downstream as return flows (Jacob et al., 2009). In addition to this the following also an opportunity for improving water use efficiency.

\subsubsection{Increasing harvest index}

The harvest index is the ratio of the economic yield to total biomass of a given crop and all agricultural system are interested for the use full part of the crop; for example, grain, seeds, fruits, vegetables and so on (Boyer and Westgate, 2004).The economic yield is very sensitive to the water balance in the plant particularly during the reproductive stage. for example, water deficit conditions during germination (Boutraa et al., 2009) or early stage of plant growth result in early senescence (Boutraa and Sanders, 2001a,b), which result in reducing grain feeling and consequently yield loss (Yang et al., 2001).water stress can affect plant reproduction and it causes ovary abortion (Boyer and Westgate ,2004) or pollen sterility (Saini and Westgate, 1999). Improvement of harvest index by increasing the rate of grain feeling and accelerating the mobilization of photo assimilates may improve water use efficiency in water scarce environment (Zhang and Yang, 2004).

\subsubsection{Deficit Irrigation}

Deficit irrigation is the application of only pre determined percentage of calculated potential water use. This method needs the use of remote sensing techniques that can detect and assess the level of plant water stress and the amount of water needed by the plant. This technology uses the plant as an indicator, to assess the plant water requirement rather than soil water status (Jones, $2004 \mathrm{a}, \mathrm{b}$ ). This method can greatly reduce the amount of water used by the plant and has the potential increase of water use efficiency. The deficit irrigation can also save water by reducing the irrigation depth by watering only the plant root zone and increasing the interval between successive irrigation. For example, at the international center of agricultural research in the dray areas (ICARDA) application of only $50 \%$ of full irrigation requirement causes a yield reduction of only 10-15\% (Zhang and Oweis, 1999). Besides this regulated deficit irrigation is very important method to improve WUE and minimize application of water to the irrigated crop. RDI is generally defined as an irrigation practice whereby a crop is irrigated with an amount of water below the full requirement for optimal plant growth; this is to reduce the amount of water used for irrigating crops, improve the response of plants to the certain degree of water deficit in a positive manner, and reduce irrigation amounts or increase the crop's WUE. There are three main RDI approaches in the production of agricultural crops, as follows.

\subsubsection{Stage-based deficit irrigation}

Stage-based deficit irrigation is defined as RDI applied at different stages of plant development, with water applied to meet full plant evapotranspiration (ET) at the critical growth stages and less applied at the non-critical growth stages. The principle behind this approach is that the response of plants to RDI induced water stress varies with growth stages and that less irrigation applied to plants at non-critical stages may not cause significant negative impact on plant productivity even though it may reduce normal plant growth. To apply this approach effectively, one must predetermine the critical growth stages for a specific crop species and cultivar and evaluate the relative sensitivity of crop plants to water deficit at various stages in their life cycle (García Del Moral et al., 2003).

\subsubsection{Partial root-zone irrigation}

Partial root-zone irrigation (also called partial root-zone drying in some literatures) is the second most popular approach of RDI. Essentially, half of the root system is irrigated with a full amount, while the remaining half is exposed to drying soil (Fig. 1,2 and 3) (Chai et al., 2016). Typically, this approach includes two types as follows: 1. Alternate partial root-zone irrigation (Fig. 1). The watering and drying of root zone are alternated in a pre-set 
frequency that allows the previously well-watered side of the root zone to dry down while fully irrigating the previously dried root zones. The drying-wetting frequency is typically decided according to water requirements of the crop species, growth stages, and soil water holding capacity at the time irrigation is applied. The irrigated and partially dried sides of the root zone are interchanged in subsequent irrigations (Reddy, 2017).

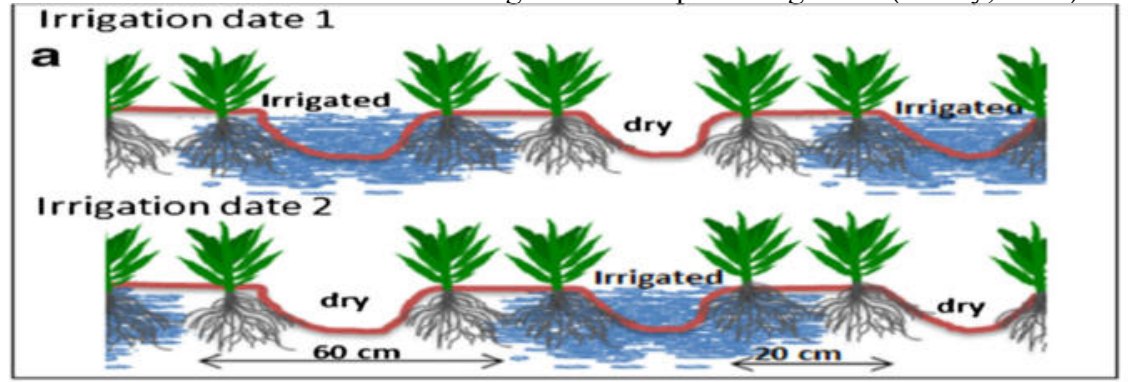

Fig. 1 Sketch of the main "regulated deficit irrigation" approaches, including alternate partial root-zone irrigation where the two neighboring plant rows in every four rows are irrigated and they are shifted in consecutive irrigations (Reddy, 2017).

2. Fixed partial root-zone irrigation (Fig. 2). During the entire growth period, approximately half of the root system is irrigated in a normal amount each time when irrigation is applied, and the remaining half is always exposed to drying soil. In both approaches, it is assumed that (i) the fraction of the root system under the drying soil may respond to drying by sending a root-sourced signal to the shoot where stomata may close to reduce water loss through transpiration (Liu et al., 2006b; Sobeih et al., 2004) and (ii) by reducing the amount of water applied to plants, a small narrowing of the stomatal opening may occur which helps reduce water loss with little or no impact on plant photosynthesis (De Souza et al., 2005; Liu et al., 2004).

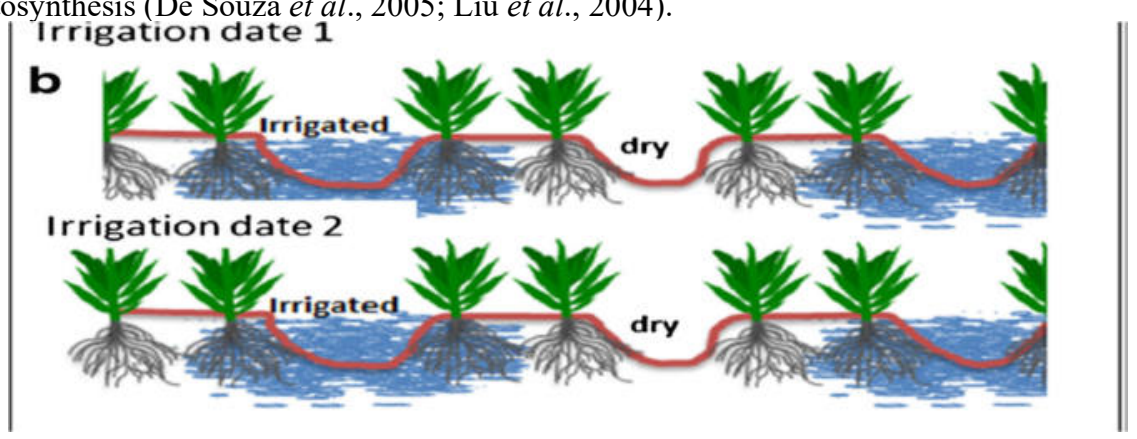

Fig. 2. Sketch of the main "regulated deficit irrigation" approaches, including, fixed partial root-zone irrigation where the two neighboring plant rows in every four rows are irrigated every time and the remaining two rows of plants kept in drying soil (Reddy, 2017).

\subsubsection{Subsurface irrigation or infiltration movement}

Subsurface irrigation is the third most popular RDI practice. Irrigation water is supplied to plants by capillary movement from the bottom (Fig.3). The root-zone air space is not immediately filled by water, in contrast with traditional irrigation where water is supplied directly overhead and water first fills the air space in the soil. Infiltration movement induces plant hardening or internal physiological regulations caused by mild water stress. A false signal of water deficit is transduced to the internals of the cell, where it induces apparent xerophytophysiological regulation with internal adjustment from the gene level to physiological levels (Xu et al., 2011). Research shows that subsurface irrigation increases crop productivity and product quality (Xu et al., 2011) 


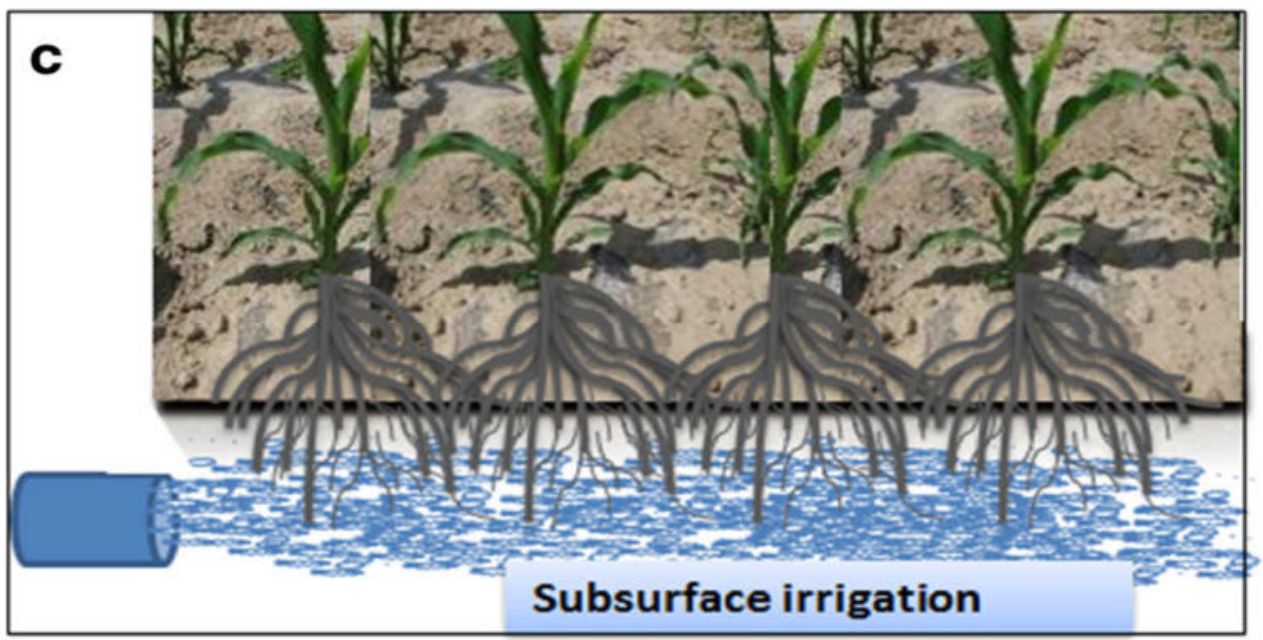

Fig. 3. Sketch of the main "regulated deficit irrigation" approaches, including, subsurface irrigation where irrigation is applied in the lower part of the root zone (Reddy, 2017).

\subsubsection{Supplemental irrigation}

Supplemental irrigation aims to add a limited amount during critical and water stress sensitive crop development stages, such as flowering and initial grain setting, or early establishment. Although this strategy has shown large potential to improve water productivity especially in semiarid and dry sub-humid cropping systems with high rainfall variability and high intra seasonal dry spell occurrence,(Barron, 2004; Pandey et al., 2001) this is not a common practice to supplement rain fed agriculture in sub-Saharan Africa. In some regions, supplementary irrigation is applied to crops in combination with soil surface covering. At the critical growth stages, dripper systems are used to provide supplemental water under the cover of plastic film. In other cases, some of the plant rows are irrigated and the other plant rows are left without irrigation but mulched with plastic films (Hu et al., 2015). In areas with crop straw readily available, straw is used to cover the soil surface of plant rows with alternate rows irrigated. All these techniques add benefits such as reduced soil evaporation and soil erosion, increased topsoil temperature with plastic cover in the early spring when soil temperatures are low and improved soil nutrient availability to crops (Gan et al., 2013; Reddy, 2017).

\section{SUMMERY AND CONCLUSION}

Due to increasing demand for food production worldwide, in regions where water is scarce, the improvement of agricultural water production become argent need. As irrigated agriculture remains vitally important as a means of food production. Enhancing water use efficiency is one of the main approaches to make better use of water. Many options to improve water use efficiency are available and the target is to produce yield with possible minimum amount of water. Despite the progress achieved in improving yield per unit of water used, major efforts still needed to deal with water shortage in order to increase food production and particular in regions where water is scarce. This goal cannot be achieved without collaborative efforts between agronomists, plant physiologists, hydrologists, molecular geneticists; agricultural engineers water experts and decision makers. Therefore, the final aim of improving WUE in irrigated agriculture is to increase the economic crop product per unit of water in water scarce environments. The effective use by the crop of a limiting water supply can be achieved by manipulating crop penology or by using agronomic techniques and practices that can be improve water use efficiency.

\section{Reference}

Ali, M.H. and M.S.U. Talukder, (2008). Increasing water productivity in crop production-A synthesis.Agric water Manage; 95:1201-1213.

Barron, J., Okwach, G. (2004). Run-off water harvesting for dry spell mitigation in maize (Zea mays L.): results from on-farm research in semi-arid Kenya. Agricultural Water Management 74(1):1-21.

Boutraa, T .and F.E. Sanders, (2001a). Effect of interactions of moisture regim and nuterent addtion on nodulation and carbon partisioning in two cultivars of bean.

Boutraa, T and F.E. Sanders, (2001b). Influence of waterstress on grain yield and vegitable growth of two cultibares of bean.Agron crop sci; 187: 251-257.

Boutraa, T ; (2010a). Effects of water stress on root growth, water use efficency, leaf area and chlorophyl content in the desert shrub calotropis procera. J . Int. Environ.Appl.Sci.,5:124-132.

Boutraa, T ; (2010a). Effects of water stress on root growth,water use efficency, leaf area and chlorophyl content in the desert shrub calotropis procera. J . Int. Environ.Appl.Sci.,5:124-132. 
Boyer, J.S. and M.E. Westgate, (2004). Grain yields with limited water. J. Exp. Botany, 55:2385-2394.

Bruinsma, J., (2003). World Agriculture: Towards 2015/2030, An FAO Perspective. Earth scan and Food and Agriculture Organization, London and Rome.

Calzadilla, A., K . Rehdanz. And R.S.J. Tol, (2010). The economic impact of more sustainable water use in agriculture: A computable general equilibrium analysis .J. Hydrol., 384:292-305.

Cattivelli, L., F .Rizza, F.W. Badeck, E. Mazzucotelli and A.M Mastrangelo, (2008). Drought tolerance improvement in crop plants: an integrated view from breeding to genomics. field crops Res., 105:1-14

De Frature, C. and D.Wicheins, (2010). Satisfaying future water demand for agriculture. Agric. water manage.,97:502-511.

De Wit, (1992). Resource use efficiency in agriculture, Agricultural Systems, 40 (1-3) (1992), pp. $125-151$.

Doll, P. (2002). Impact of climate change and variability on irrigation requirements: A global perspective. Clim. Chang. 54, 269-293.

Doll,P .and S. Siebert, (2002). Global modelling of irrigation water requirements. Water Res.,38:1037-1037.

FAOSTAT, (2006). FAO Data for agriculture: statics database. FAOSTAT., Rome, Italy.

Faure`s, J., Svendsen, M., Turral, H., (2007). Reinventing irrigation. In: Molden, D. (Ed.), Water for Food, Water for Life: A Comprehensive Assessment of Water Management in Agriculture. Earth scan and International Water Management Institute, London and Colombo.

Gamo, M ., (2009). Classification of arid region by climate and vegitation. J Arid Land Study., 1:9-17.

Gan, Y., Siddique, K.H.M., Turner, N.C., Li X.G., Niu, J.Y., Yang, C., Liu, L. and Chai, Q. (2013). Ridge-furrow mulching systems an innovative technique for boosting crop productivity in semiarid rainfed environments. Adv.Agron.118: 429-476.

Hong-Xing, C., Z. Zheng-Bin, X. Ping, C.Li-Ye, S. Hong-Bo, L. Zhao-Hua and L. Jun-Hong, (2007). Mutual physiological genetic mecanism of plant high water use efficency and nuteration use efficency.colloids Surf. B :Biointerfaces, 57:1-7.

Hu, F, Chai, Q., Yu, A., Yin, W., Cui, H. and Gan, Y.(2015). Less carbon emissions of wheat-maize intercropping under reduced tillage in arid areas. Agron. Sustain. Dev.35:701-711.

IPCC, (2007) .Climate change 2007: the physical sciences basis.

Jacob, Daniel J., and Darrel A. Winner, (2009). Effect of climate change on air quality. Atmospheric Environment 43(1):51-63.

Jones, H., (2004b). Water use efficency in plant biology. In water use efficency in plant biology,Bacon, M.(Ed.). Blackwell,Oxford, UK.

Jones, H.G., (2004a). Application of terminal imaging and inferared sencing in plantphysiology and ecophysiology. Adv. Botany Res., 41:107-163.

Jyun-Long Lee and Wen-Cheng Huang, (2014). Impact of Climate Change on the Irrigation Water Requirement in Northern Taiwan.

Karoun, M and M. El-Mourid, (2009). Improving water productivity of crops in the medeteranian region:case of cereals.pp:123-130.

Keller, A and Seckler, D. (2004). Limits to Increasing the Productivity of Water in Crop Production Winrock Water, Arlington, VA (2004).

Liu, F., Shahnazari, A., Andersen, M.N., Jacobsen, S.E. and Jensen, C.R., (2006). Physiological responses of potato (Solanumtuberosum L) to partial root-zone drying: ABA signaling, leaf gas exchange, and water use efficiency. J. Exp. Bot.57: 3727-3735.

Molden, D., (2007). Water for food water for life: Acomprehensive assesment of water management in agriculture.sinternational water management institute, Battaramulla,Sri Lanka,pp688.

Molden, D., Oweis,T., Steduto, P., Bindraban, P., Hanjra, M. A., Kijne, J., (2009). Improving agricultural water productivity: Between optimism and caution. Agricultural Water Management 97 (2010) 528-535.

Morison,J.T, N.R Baker, P.M. Mulluneaux and W.J Davies, (2008). Improving water use in crop production. Philo. Trans. R. Soc. London B Biol. Sci., 12:639-658.

Pandey, R.K., Maranville, J.W., Admou, A. (2001). Tropical wheat response to irrigation and nitrogen in a Sahelian environment. I. Grain yield, yield components and water use efficiency European Journal of Agronomy 15(2): 93-105.

Parry, M A.J., J.Flaxas and H. Medrano, (2005). Prospects for crop production under drought:research priorities and future directions. Ann. Applide Biol.,147:211-226.

Passioura,J., (2006). Increasing crop productivity when water is scarce-from breeding to fild management . Agric. Water Manage., 80:176-196.

Perry, C., P. Steduto,G.R. Allen and C.M. Burt, (2009). Increasing productivity in irrigated agriculture: agronomic concentrates and hydrological realities. Agric. Water Mange., 96:1517-1524.

Reddy S.R. and Prayasi Nayak, (2017). Crop production with limited irrigation. Kalyani Publishers, Ludhiana, India. 
Sayre K.D., Rajaram S., Fische R.A., (1997). Yield potential progress in short bread wheat in Northwest Mexico Crop Science, 37 (1) (1997), pp. 36-42.

Seckler, D., Molden, D., Amarasinghe, U., de Fraiture, C., (2000). Water Issues for 2025: A Research Perspective. International Water Management Institute, Colombo.

Seckler, D., Molden, D., Sakthivadivel, R., (2010). The concept of efficiency in water resources management and policy. In: Kijne, J.W., Barker, R., Molden, D. (eds.). 2010. Water productivity in agriculture: Limits and opportunities for improvements. Comprehensive Assessment of Water Management in Agriculture Series 1, CABI International, UK.

Shao, H.B., Z.S. Liang, M.A. Shaoand B.C. Wang, (2005). Impacts of PEG-6000 pretreatment for barly seeds on the effect of their mature ebrayo invetro culture and primary investigation on its physiological mechanism. Colloids Surfaces B: Biointerfaces,41:73-77.

Steduto P., Hsiao T.C., Fereres E., (2007). On the conservative behavior of biomass water productivity Irrigation Science, 25 (2007), pp. 189-207.

Tanner C.B. and Sinclair T.R., (1983). Efficient water use in crop production: research or re-search? H.M. Taylor, W.A. Jordan, T.R. Sinclair (Eds.), Limitations to Efficient Water Use in Crop Production, American Society of Agronomy, Madison, WI (1983).

Viets, F.G., (2008). Fertilizer and efficient use of water. Advances in Agronomy 14: 223264.

Xu H.L., Qin, F.F., Xu, Q., Xu, R.Y., Wang, T.Y. and Wang, R., (2011). Applications of xerophytophysiological in plant production: sub-irrigation improves tomato fruit yield and quality. J. Food Agric. Environ.9: 256263.

Yang,J., J. Zhang,Z. Wang,L. Liu and Q. Zhu, (2001). Remobilization of carbon reserves in response to water deficit during grain filling in rice .field crop Res.,71:47-55.

Zhang, H. and Oweis T., (1999). Water-yield relations and optimal irrigation scheduling of wheat in the medetranian region. Agric. Water Manage., 38:195-211.

Zhang, J .and Yang J., (2004). Improving harvest index is an effective way to increase crop water use efficiency. Proceedings' of the $4^{\text {th }}$ international crop sciences congerence on the theme crop sciences for diversified planet, sept. 21-25, Brisbane, pp:1-7. 